sun, and it is also equal to $-h \Delta \nu$, where $\Delta \nu$ is the increase of frequency of the light quantum. Thus $\Delta \nu=$ $-\left(2 \nu^{2} h / c^{2} m\right) \sin ^{2} \delta / 2$, and $\Delta \lambda=-c \Delta v / \nu^{2}=(2 h / c m) \sin ^{2} \delta / 2$, a value which is independent of the wave-length, at any rate if $\delta$ be so.

For a light quantum passing close by the sun we have $m=2$. I $\mathrm{O}^{33} \mathrm{gm} ., \delta=\mathrm{I} \cdot 75^{\prime \prime}=8 \cdot 5$. IO $^{-6}$ radian; hence with $h / c=2 \cdot I 8 \cdot I^{-37}$ we find $\Delta \lambda=3 \cdot 9 \cdot I^{-81} \mathrm{~cm}$., a change which is far too small to be detected by experiment.

If, however, we assume that the negative electron behaves like a very minute gravitating mass, though acting according to a different law on account of its charge, we obtain a connexion with A. H. Compton's recent quantum theory of the scattering of X-rays (Physical Review, May 1923, p. 483). Although this theory in its present form does not account for the excess scattering, it is very successful in explaining the small scattering of $\gamma$-rays as well as their softening. To this extent it supports the present view of the deflexion of light. I have worked out the orbits of light corpuscles for a gravitating electric charge, but the full discussion of the results and of their bearing on the structure of the electron must be reserved for the paper already referred to. G. A. Schotт.

University College of Wales, Aberystwyth, September 3 .

\section{Suggested Botanical Exploration of the Higher Summits of the Cape Verd Islands.}

IT is somewhat surprising that in our much explored world there is still a group of large islands in the Atlantic which in a botanical and probably also a zoological sense may be said to be imperfectly known. For until we know what lives on the cloudcapped summits of islands like Fogo and San Antonio, which attain elevations of 8000 and 9000 feet above the sea, it can scarcely be said that the Cape Verd Islands have been scientifically explored. Surely here would be a good piece of work for an English yachtsman and two or three investigators from Lisbon. Allowing two weeks for each island, the examination of Fogo and San Antonio would only involve about a month's absence from St. Vincent, the assumed starting-place, and a host of botanical and other curiosities would be gathered in the deep ravines and on the uplands of those mountainous islands. With government aid it could be carried out by one of the learned societies of Lisbon.

Fogo is reckoned to be the healthiest of the islands; and it promises to be the most interesting for the naturalist. But whoever goes will have to be prepared for living in damp conditions, as in perpetual fog and mist.

Anything may be in hiding on those cloud-capped uplands. Concealed in the ravines may still survive plants that have become extinct in other Atlantic groups, or which exist only in islands of other oceans or in distant parts of the world, such as the TreeCompositæ of St. Helena, the Tree-Labiatæ of Juan Fernandez, the Tree-Lobelias of the mountains of tropical Central Africa.

Then, again, American genera, like Clethra, that have died out in the Canary Islands, may still survive in the Cape Verd group, and the same may be said of numerous other plant-types that have died out in other parts of the world, or are almost extinct there. Within the rain-belt of these mountainous islands may still linger remains of once predominant laurel woods and their associated plants, such as are now so characteristic of the Azores, Madeira, and the Canaries.

The most significant features of island-floras are presented in their connexions with distant regions, and it is on this feature that are largely based the hopes of important results arising from the examination of the summits of the mountainous islands of the Cape Verd group. Thus, Tree-Lobelias link Hawaii in the Pacific Ocean with the highlands of Kilimanjaro in tropical Africa; the islands of Bourbon and Mauritius in the Indian Ocean possess species of Acacia trees that are scarcely distinguishable from a tree common in the Hawaiian mountains. So again the affinities of the endemic genera of Juan Fernandez connect its flora with St. Helena, the Canary Islands, and the Chatham Islands. The distant connexions of the endemic genera of the Socotran flora are equally remarkable. They cover much of the globe and are found in Asia, Africa, and America.

As Hooker urged in his lecture on insular fioras, islands have frequently served as sanctuaries for plant-types that have become extinct on the continents, and in the same way we would expect the Cape Verd Islands to harbour the kith and kin of many plant-types that have failed in the struggle for existence in distant parts of the world.

We cannot afford to let slip opportunities of this kind for increasing botanical knowledge. The island of Fogo has probably already lost much of its original flora through the agency of the woodcutter, and not many trees remain. Barker-Webb, Hooker, Schmidt, Krause, Vogel, Christ, Hemsley, and Coutinho have done much to elucidate the plant-history of the Cape Verd Islands, but the most interesting features of their flora may be not yet disclosed.

Red House, Fowey, Cornwall,

H. B. Guppy. August 29.

\section{Polar Temperatures and Coal Measures.}

I THANK Mr. Bonacina for his sympathetic comment in NATURE of September 22, p. 436, on my letter on "Polar Temperatures and Coal Measures" and for the added clarity he has brought to this subject. He mentions disagreement with me on one minor issue only, and that relating to the south polar regions. In that connexion I am glad of the opportunity to confess that my thinking on the subject of polar coal measures has really been based almost exclusively upon my knowledge of the Arctic. My suggestion that similar conditions might explain Antarctic coal was a sort of parenthetical remark made without any special consideration of the Antarctic problem.

Mr. Bonacina says: "I do not, however, fully support Dr. Stefansson in expecting that a lowland south polar continent surrounded by an ice-chilled ocean would be liable, at least so often, to the high summer temperature of the Arctic lowlands." A reading of Mr. Bonacina's letter in comparison with mine will show that this partial disagreement is apparent only, due to my faulty expression. I did not mean to say that if the postulated low Antarctic continent were somewhat larger than the actual present continent, high temperatures would be as frequent there as they would be in the Arctic if the land masses of North America and Asia were connected across the North Pole by continuous low land. All I meant to say was that such a hypothetical low southern continent might have temperatures high enough for the development of a coniferous forest.

Mr. Bonacina gives the explanation which I have supposed correct for the lowering of summer temperatures in the northern Mackenzie valley by almost continuous winds blowing from the north.

$$
\text { NO. } 28 \text { I } 3 \text {, VOL. I I } 2]
$$

